\title{
DIRECTED NATURAL FORCES OF AFFINITY BETWEEN A BACTERIUM AND MINERAL
}

\author{
STEVEN K. LOWER \\ Ohio State University, 125 South Oval Mall, 275 Mendenhall Laboratory, Columbus, \\ Ohio 43210 USA; Lower.9@osu.edu
}

\begin{abstract}
The formation of a bond between a bacterium and a mineral is ultimately controlled by forces that operate over length scales of a few nanometers. This manuscript presents evidence that bacteria may actively modulate forces at the cell-mineral interface to promote contact with specific mineral phases. Nano- to pico-Newton forces were measured between goethite $(\mathrm{FeOOH})$ and each of two species of Gram negative bacteria (Escherichia coli and Shewanella oneidensis) in aqueous solution of varying oxygen concentration. The interactions were dominated by electrostatic and steric forces as either bacterium approached to within 10 to $12 \mathrm{~nm}$ of the surface of goethite. The van der Waals force exhibited an influence on each bacterium-mineral pair at separations of $\sim 2 \mathrm{~nm}$. These types of nonspecific forces were all that were observed for the $E$. coli-goethite pair. However, S. oneidensis exhibited a selective disposition to form a specific bond with goethite, particularly under anaerobic conditions. These data suggest that $S$. oneidensis is able to perceive and recognize the surface of metal oxyhydroxides and regulate attractive forces at the cell-oxide interface. This may be a vestige of the close evolutionary linkage between iron oxyhydroxides and metal-reducing bacteria like Shewanella, which can use Fe(III) in the crystal structure of a mineral as a terminal electron acceptor.
\end{abstract}

\section{INTRODUCTION}

Few things in nature are as specific as the interactions between a protein and its complementary ligand. Intra and intermolecular forces between reactive functional groups direct the specificity of such reactions. For quite some time, such specificity has been known to focus cell-cell binding reactions within biofilms inhabiting the human oral cavity (Kolenbrander, 1989; Whittaker and others, 1996). In such environments, steriospecific "fit" has been identified as the primary factor controlling the binding of a particular bacterium to another cell or organic conditioning film (Ellen and others, 1997). Tantalizing hints that such affinity may exist between bacteria and inorganic surfaces can be found in the literature. For example, some researchers have shown that Acidithiobacillus ferrooxidans expresses an affinity for particular sulfide minerals that serve as a source of electrons for energy generation (Devasia and others, 1993; Ohmura and others, 1993; Arredondo and others, 1994; Ohmura and others, 1996; Dziurla and others, 1998). However, these types of studies rely on indirect evidence for bacterium-mineral "recognition", such as, microscopy images that show a higher number of cells attached to one mineral relative to another.

Lower and colleagues have recently measured intermolecular forces between Shewanella oneidensis and iron versus aluminum hydroxides (Lower and others, 2001a; Lower and others, 2002). These data have provided the first direct evidence that bacteria may indeed recognize inorganic crystalline surfaces by directing natural forces of affinity from cell-surface biopolymers towards a mineral face. The work contained herein will explore further the specific nature of biological recognition of inorganic surfaces by presenting force microscopy measurements between goethite $(\mathrm{FeOOH})$ and S. oneidensis versus Escherichia coli. Both of these microorganisms are Gram negative bacteria meaning that the general composition and architecture of their outer surfaces are very similar. Figure 1 presents the external face of the outer membrane $(\mathrm{OM})$ of a Gram negative bacterium. 


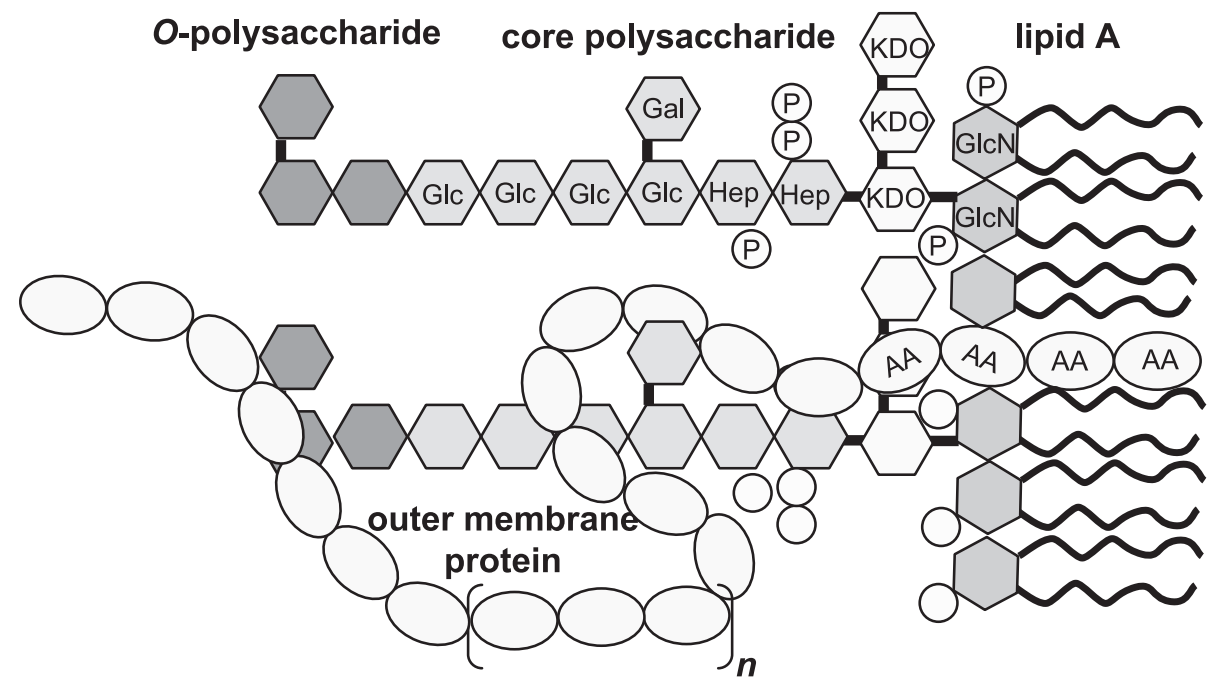

Fig. 1. Schematic diagram showing the general architecture and biomolecular structure of the exterior cell surface of Gram negative bacteria (based on the work of Beveridge, 1981; Nikaido, 1996; Raetz, 1996; Rick and Silver, 1996; Beveridge, 1999; Madigan and others, 2003). The force microscope used in this study allows one to probe forces between a mineral surface and biological molecules on a living cell. The force microscope is also capable of measuring the biomechanical topology of macromolecules (such as, outer membrane proteins) that form a bond with a mineral surface. Abbreviations are as follows: $N$-acetylglucosamine $(\mathrm{GlcN})$, phosphate $(\mathrm{P})$, ketodeoxyoctonate (KDO), heptose sugar (Hep), glucose (Glc), galactose $(\mathrm{Gal})$, amino acid (AA), repeating amino acid residues (brackets with an " $n$ " subscript). The Gram-negative strains used in this study (E. coli K12 and $S$. oneidensis MR-1) possess only the core oligosaccharide and lack the $O$-side chain (T. Beveridge, personal communication).

Each cell is surrounded by a lipid-protein membrane called the outer membrane $(\mathrm{OM})$. The outer face of the OM is composed of a lipopolysaccharide (LPS), which is made of three distinct parts: lipid A, which anchors the LPS into the OM; a core polysaccharide, which contains ketodeoxyoctonate and several hexose and heptose sugars; and an $O$-polysaccharide, which consists of strain-specific sugar residues (see fig. 1). The polysaccharide chains of the LPS extend 2 to $40 \mathrm{~nm}$ outwards from the cell wall, depending on the bacteria strain (Nikaido, 1996; Pink and others, 2003; Stoica and others, 2003). The OM also contains a number of proteins composed of relatively long chains of amino acids. Some of these proteins are inducible and are expressed under specific physiological conditions, while others are constitutive or expressed under all growth conditions.

The fact that the outer surfaces of both $E$. coli and $S$. oneidensis are very similar (see fig. 1) suggests that either bacterium should interact with goethite in much the same fashion. Nonspecific forces such as van der Waals and electrostatic interactions would be expected to governor how or if an interface is formed between goethite and E. coli or $S$. oneidensis. However, one must also consider the fact that $S$. oneidensis, unlike E. coli, has outer membrane proteins that are capable of shuttling electrons to $\mathrm{Fe}$ (III) in minerals under anaerobic conditions. (Myers and Myers, 1992, 1993, 1997; Myers and Myers, 1998, 2001; Myers and Myers, 2003). This has lead some researchers to conjecture that dissimilatory metal reducing bacteria like Shewanella, were among the first biological cells to inhabit and propagate the early Earth, which did not have oxygen as a terminal electron acceptor (Lovley, 1991; Vargas and others, 1998). Presumably, these early metal reducing bacteria evolved the proteins that their present day counterparts possess for energy generating reactions in which electrons are 
shuttled from a bacterium to Fe(III) in the crystal structure of a mineral. It is possible that this intimacy between metal reducing bacteria and ferric containing minerals is preserved in the genetic makeup of a species such that $S$. oneidensis expresses a natural and selective affinity for metal hydroxides, like goethite, that may serve as terminal electron acceptors under deoxygenated conditions.

This study presents evidence that $S$. oneidensis forms specific bonds with metal oxyhydroxides. This was accomplished by using a force microscope to probe inter-and intra-molecular forces between goethite and S. oneidensis versus E. coli. The observed force measurements were compared to theoretical models describing van der Waals, electrostatic, and steric forces between goethite and each of the two Gram-negative bacteria. These experiments indicate that E. coli and S. oneidensis perceive a mineral surface through intermolecular forces that operate over length scales of a few nanometers. S. oneidensis actively regulates forces at the goethite interface by targeting proteins to the cell wall, which in turn form specific bonds with goethite.

METHODS

\section{Growth of Bacteria and Preparation of Biologically-Active-Force-Probes}

E. coli K12 was purchased from BioRad Laboratories (Hercules, CA) and cultured in $25 \mathrm{~g} / \mathrm{L}$ Luria-Bertani (LB) medium (Fisher Scientific, Pittsburg, PA) at 22 to $25^{\circ} \mathrm{C}$ and $\mathrm{pH} \sim 7$. S. oneidensis MR-1 (ATCC 700550) was purchased from the American Type Culture Collection (Manassas, VA) and cultured in LB medium or in defined M1 medium (Myers and Nealson, 1990) at 22 to $25^{\circ} \mathrm{C}$. For anaerobic cultures of $S$. oneidensis, LB or M1 medium was supplemented with $15 \mathrm{mM}$ lactate as the carbon and energy source and $2 \mathrm{mM}$ ferric citrate as the electron acceptor.

For aerobic growth of each bacteria species, a glass bottle containing LB or M1 medium was inoculated with an overnight, aerobic culture and grown with vigorous aeration using a shaker table. Anaerobic growth of $S$. oneidensis was performed inside an anaerobe chamber (Coy Laboratory Products, Ann Arbor, MI) with anaerobic media and solutions. E. coli or S. oneidensis cells were harvested at mid to late exponential growth phase by centrifugation. These cells were rinsed in sterile $\mathrm{NaCl}$ solutions and used immediately to fabricate biologically-active-force-probes.

Biologically-active-force-probes were created with E. coli or S. oneidensis cells as described previously (Lower and others, 2000; Lower and others, 2001b; Kendall and Lower, 2004). Briefly, glass beads $(\sim 10 \mu \mathrm{m}$ diameter $)$ were coated with amino-silane, washed to remove excess silane, and then placed in a suspension of bacterial cells. A single bacteria-coated bead was then attached to the end of a silicon nitride cantilever with epoxy. As shown previously (Lower and others, 2001a), the silane molecule does not have any impact on the observed forces as it is confined to the interface between the bacteria and glass bead, rather than the surface of the bacteria that will interact with a mineral during force measurements. Further, the silane linker did not appear to harm the cells as the bacteria were still viable after their use. This was confirmed by placing a biologically-active-force-probe on an agar plate subsequent to force measurements. For the data presented herein, a distinct, single colony was observed under the end of each of the cantilevers.

Scanning laser confocal microscopy was used to image each force-probe prior to its use in the force microscope (Lower and others, 2000). Prior to fabricating biologically-active-force-probes, bacteria were transformed with a plasmid for the green fluorescence protein, pSMC2, kindly provided by G. O'Toole (Lower and others, 2000; Lower and others, 2001a). The position of E. coli or S. oneidensis cells on a cantilever could be imaged by detecting the fluorescent signal emitted by living cells. It was impossible to control the orientation of bacterial cells on a bead attached to the cantilever. Therefore, the true contact geometry of a bacterial cell is not known. 


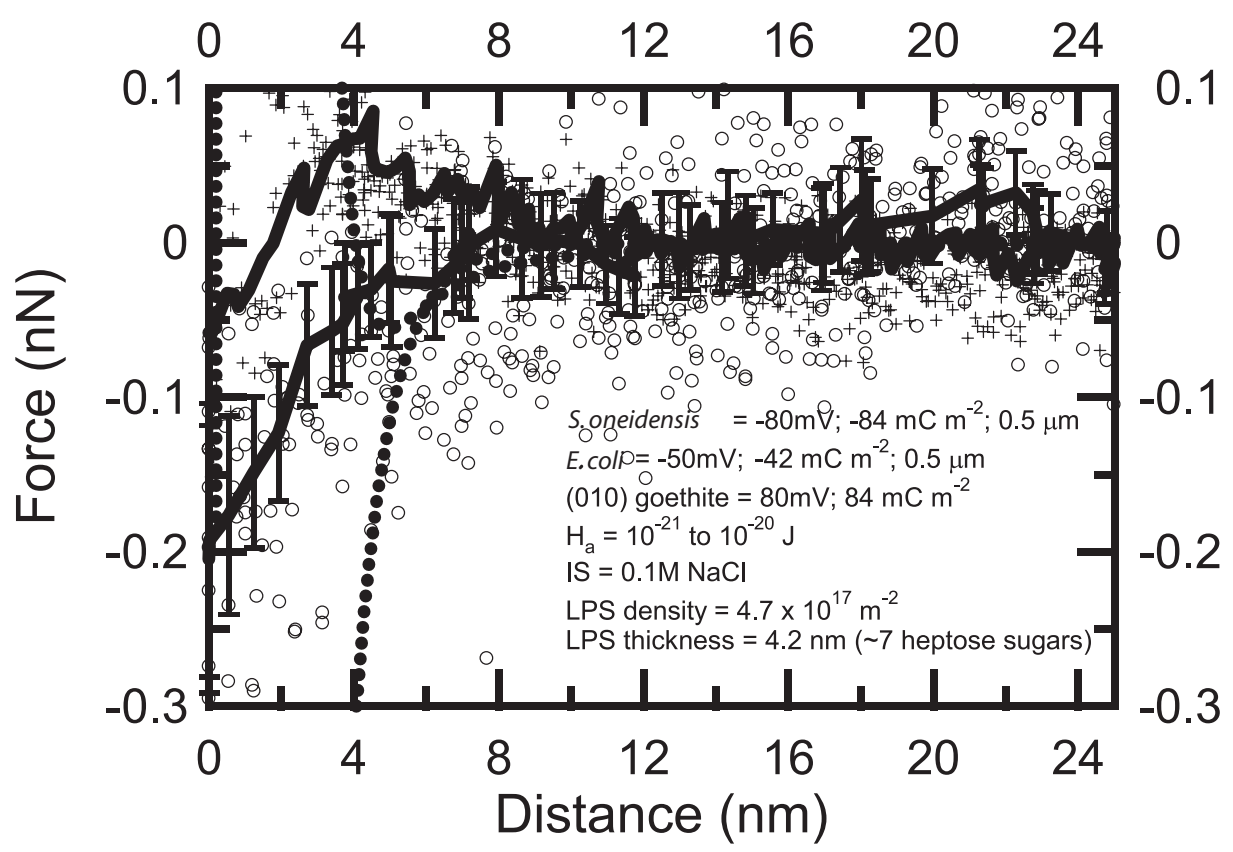

Fig. 2. Forces recorded as the (010) surface of goethite $(\mathrm{FeOOH})$ approaches either E. coli (cross symbols) or $S$. oneidensis (open circles) in a $0.1 \mathrm{M} \mathrm{NaCl}$ solution at circumneutral $\mathrm{pH}$. The two solid black curves show the average values for E. coli and S. oneidensis. Error bars, corresponding to the $95 \%$ confidence interval, are shown for the $S$. oneidensis data. Error bars are omitted from the $E$. coli data for clarity. Repulsive forces have a positive sign, whereas attractive forces are negative. Dotted, black lines correspond to the theoretically predicted intermolecular forces calculated using the DLVO theory (eqs. 1 and 2) and "extended" DLVO theory (eqs. 1, 4, and 5). Parameters for these models were taken from table 1 and are listed on the figure. Abbreviations are as follows: Hamaker constant $\left(\mathrm{H}_{\mathrm{a}}\right)$, IS (ionic strength), LPS (lipopolysaccharide).

\section{Biological Force Microscopy Measurements and Data Analyses}

Commercial force microscopes (NanoScope IIIa Multimode SPM and NanoScope IV Bioscope, Veeco-Digital Instruments) were used to measure attractive or repulsive forces between each of the two bacterial species and the (010) face of goethite $(\mathrm{FeOOH})$ in aerobic or anaerobic solutions at circumneutral $\mathrm{pH}$ and 10 to $100 \mathrm{mM}$ $\mathrm{NaCl}$. Forces were measured as a bacterium approached and was subsequently retracted from the surface of goethite. Approach force data were compared to theoretical models describing nonspecific forces such as van der Waals, electrostatic, and steric forces between a bacterium and the surface of goethite. Retraction force data were searched for evidence of specific forces of interaction between a bacterium and goethite. The operation of a force microscope has been described previously (Lower and others, 2000; Lower and others, 2001b). The specifics of these particular force measurements are described in detail by Lower and others (see this issue of the American Journal of Science). It should be noted that atomic force microscopy, biological force microscopy, and force microscopy are all names describing the same force measuring technique.

RESULTS

In a typical experiment, approach and retraction forces were measured after varying the contact time between goethite and either S. oneidensis or E. coli in aerobic or anaerobic solutions. Figure 2 illustrates intermolecular forces that were detected at a 


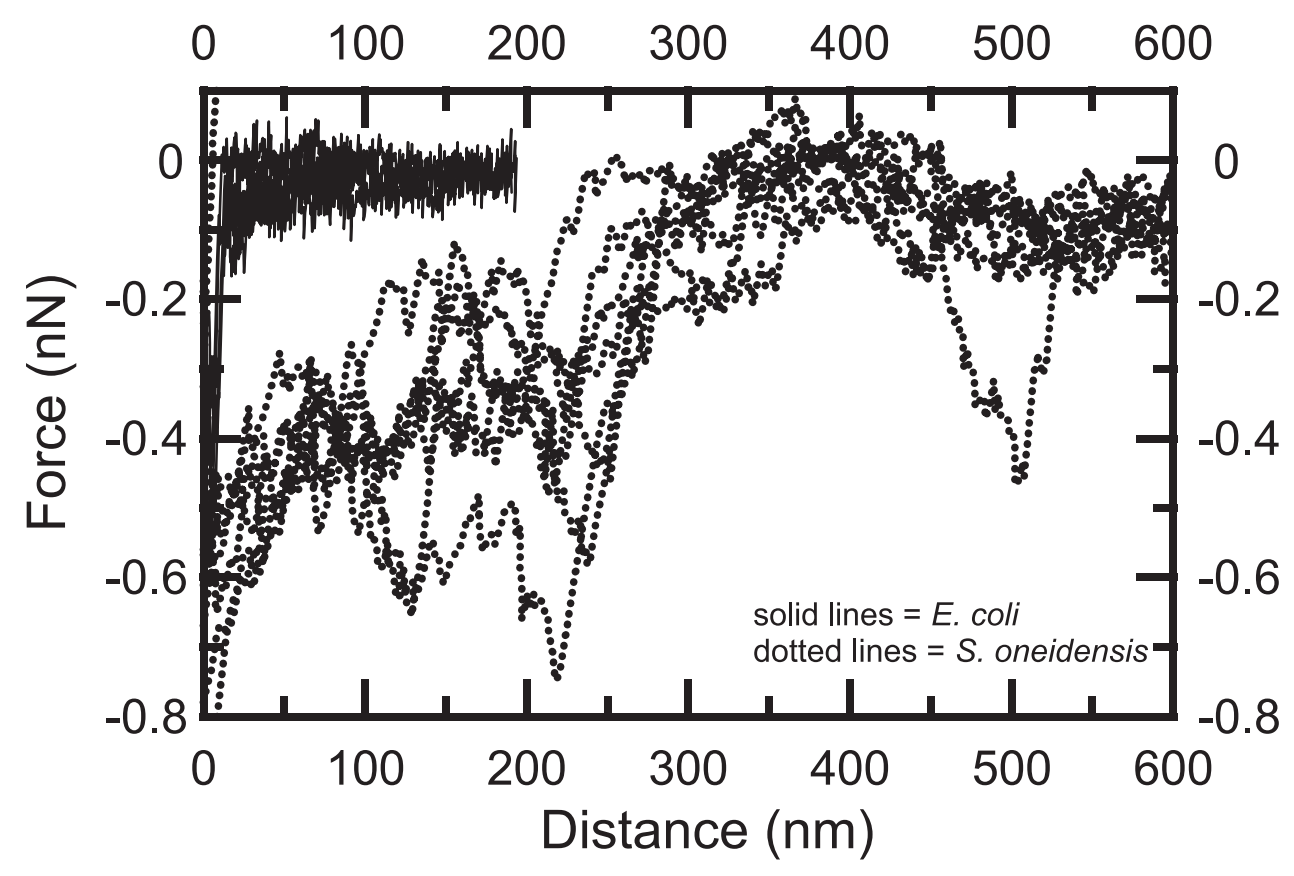

Fig. 3. Forces recorded as the (010) surface of goethite is retracted from E. coli in aerobic solution (upper, solid black lines) or $S$. oneidensis in anaerobic solution (lower, dotted black lines). All forces shown here are negative which indicates attraction.

bacterium-goethite interface upon approach of the cells towards the mineral. As $S$. oneidensis approached to within $8 \mathrm{~nm}$ of the goethite surface, attractive forces caused the bacterium to make contact with the mineral to a maximum force of $0.2 \mathrm{nN}$ (fig. 2). E. coli experienced similar forces with the exception that a repulsive force of $\sim 0.05 \mathrm{nN}$ preceded the attractive "jump to contact" feature, which was observed to occur at a separation of $4 \mathrm{~nm}$ (fig. 2). Another notable difference was that the maximum attractive force between $E$. coli and goethite $(-0.05 \mathrm{nN})$ was less than that for goethite and $S$. oneidensis $(-0.20 \mathrm{nN})$. In general, the forces measured upon approach were similar for either of the two species of Gram negative bacterium. Neither bacterial species experienced any type of interaction until they were within $10 \mathrm{~nm}$ of the mineral surface. Further, both $E$. coli and $S$. oneidensis experienced an attractive force once contact was established with the (010) surface of goethite.

Figure 3 shows the retraction measurements collected between goethite and each of the two bacteria species. E. coli exhibited an average adhesive force towards goethite of $\sim 0.35 \mathrm{nN}$. While a few retraction traces exhibited longer range force interactions, $E$. coli typically broke free of any force fields at a distance of $\sim 10 \mathrm{~nm}$ (see fig. 3). This separation length is similar to the distance at which $E$. coli first felt the goethite surface upon approach (see fig. 2).

$S$. oneidensis, on the other hand, exhibited a very different relationship with goethite upon being pulled away from the mineral surface (fig. 3). The S. oneidensis retraction curves display a much stronger affinity at contact particularly under anaerobic conditions. Another notable difference is the jagged, "sawtooth" like profile, which appear to be a hallmark signature for $S$. oneidensis interactions with goethite under anaerobic conditions. These sawtooth features are regions of the retraction curve where the force increases nonlinearly and then recoils back towards zero force. Some sawteeth extend outwards for more than $500 \mathrm{~nm}$. 
It should be noted that the amount of contact time played a significant role in determining whether sawtooth patterns were detected in the retraction profiles. There was a very strong, positive correlation between the amount of time $S$. oneidensis spent in contact with goethite and the number of sawtooth features detected in the retraction profiles. In general, contact times greater than 20 to 30 minutes resulted in far more sawtooth features in the force curves. No such relationship was noted for E. coligoethite retraction curves. As mentioned above, most retraction traces between E. coli and goethite did not even contain sawtooth signatures.

\section{DISCUSSION}

The results discussed above present quantitative measurements of pico- to nanoNewton forces between the (010) surface of goethite and each of two living bacteria $(E$. coli and $S$. oneidensis) in aqueous solution. These measurements reveal two distinct force-distance relationships between a bacterium and mineral, that is, those forces observed upon approach of a cell towards a mineral versus the force-distance relationship observed when a cell is pulled from contact with a mineral. These two data sets will be interpreted with several well-established theoretical constructs that describe forcedistance relationships between surfaces. The discussion below will demonstrate that the approach data describe nonspecific intermolecular forces that govern the approach of a bacterium towards the mineral; whereas the retraction data probe specific interactions between goethite and macromolecules on the outer surface of a bacterium.

Over fifty years ago, four scientists presented a theory that is now widely known as the DLVO model (Derjaguin and Landau, 1941; Verwey and Overbeek, 1948). Originally developed to understand dispersion and aggregation phenomena of colloids in solution, it has since been used to study the intermolecular forces at the cell-mineral interface. The DLVO theory sums van der Waals and electrostatic interactions to determine attractive or repulsive energy ( $E$ in Joules) or force ( $F$ in Newtons) as a function of the distance $(D)$ between a bacterium and mineral in aqueous solution. Force and energy are related via $F(D)=-d E(D) / d D$, which defines the force at a specified distance as the negative of the energy gradient at that distance. In general, the van der Waals force is attractive, while the electrostatic force may be attractive for particles of unlike charge, or repulsive for particles with the same sign of charge.

The van der Waals expression describing the interactions between a bacterium, treated as a sphere, and goethite, treated as a flat plane, is given by (Israelachvili, 1992; Butt and others, 1995; Leckband and Israelachvili, 2001)

$$
F(D)=\frac{-H_{a} r}{6 D^{2}}
$$

where, $H_{a}$ is the Hamaker constant (in $\mathrm{J}$ ), $D$ is the separation distance (in $\mathrm{m}$ ) between the sphere and flat plane, and $r$ (in $\mathrm{m}$ ) equals the radius of the sphere. The van der Waals force arises because of spontaneous electrical and/or magnetic polarizations between particles at close separation (Israelachvili, 1992; Elimelech and others, 1995).

The electrostatic force, which arises between charged particles, is a more complicated interaction to model. Commonly, this force type is described by approximating a solution to the Poisson-Boltzmann equation, which provides a mathematical relationship between a particle's charge density and electrical potential in an electrolyte solution (Elimelech and others, 1995). Among the most common approximations cited in the literature are the linear superposition approximation of Gregory (1975) and the constant potential approximation of Hogg and others (1966). The reader is referred to Elimelech and others (1995) for a thorough description of these and other approximations such as the constant charge approximation. 
Gregory's linear superposition model (1975) for electrostatic forces between a sphere and flat surface is:

$$
F(D)=64 \pi r \varepsilon \varepsilon_{0} \kappa\left(\frac{k_{B} T}{z e_{c}}\right)^{2} \gamma_{1} \gamma_{2} \mathrm{e}^{-\kappa D}
$$

where $D$ and $r$ are defined as above, $\varepsilon$ is the dielectric constant of water (78.54 at 298 $\mathrm{K}), \varepsilon_{0}$ is the permittivity of free space $\left(8.854 \times 10^{-12} \mathrm{C}^{2} \mathrm{~J}^{-1} \mathrm{~m}^{-1}\right), k_{B}$ is Boltzmann's constant $\left(1.381 \times 10^{-23} \mathrm{~J} \mathrm{~K}^{-1}\right), T$ is temperature (in $\left.\mathrm{K}\right), z$ is the valence of electrolyte ions $(1 \mathrm{for} \mathrm{NaCl})$, and $e_{c}$ is the charge of an electron $\left(1.602 \times 10^{-19} \mathrm{C}\right)$. The inverse Debye length $\left(\kappa\right.$, in $\left.\mathrm{m}^{-1}\right)$ describes the thickness of the diffuse double layer of counterions that surrounds charged particles in solution. For monovalent electrolytes at $298 \mathrm{~K}$, the Debye length $\left(\kappa^{-1}\right.$, in $\left.\mathrm{nm}\right)$ is given by $0.304 /(c)^{1 / 2}$, where $c$ is the concentration of the electrolyte $\left(\mathrm{mol} \mathrm{L}^{-1}\right)$. The final parameter in Gregory's equation is the dimensionless surface potential $(\gamma)$ described as

$$
\tanh \left(\frac{\mathrm{z} e_{c} \psi_{x}}{4 k_{B} T}\right)
$$

where $\psi_{x}$ is the surface potential (in V) of particle " $x$ ", and the other parameters $\left(z, e_{c}\right.$, $k_{B}$, and $\left.T\right)$ are as defined above.

Hoggs' constant potential model (1966) for electrostatic forces between a sphere and flat surface is:

$$
F(D)=-2 \pi r \varepsilon \varepsilon_{0} \kappa\left(\frac{k_{B} T}{z e_{c}}\right)^{2}\left(\frac{\phi_{1}^{2}+\phi_{2}^{2}-2 \phi_{1} \phi_{2} \mathrm{e}^{\kappa D}}{\left(\mathrm{e}^{\kappa D}-1\right)\left(\mathrm{e}^{\kappa D}+1\right)}\right)
$$

where parameters are as defined above. The reduced potential $\left(\phi_{x}\right)$ of particle " $x$ " (that is, a bacterium or mineral) is equal to $\left(z e_{c} \psi_{x} / k_{B} T\right)$. In most cases, a particle's zeta potential $(\zeta$, in $V)$ is used as a proxy for the surface potential $(\psi)$ in equations describing the electrostatic force.

Figure 4 shows the theoretical van der Waals and electrostatic forces between goethite and a Gram negative bacterium under different conditions. The surface potential (or surface charge) and Hamaker constant for these particular bacteriamineral-solution systems were taken from values published in the literature (table 1). Both the van der Waals and electrostatic forces are expected to be attractive for either bacterial species interacting with goethite (see fig. 4). Neither force is expected to extend beyond a length scale of $\sim 10 \mathrm{~nm}$. In general, the electrostatic force is expected to be larger range than the van der Waals force. Although, for a Hamaker constant of $10^{-20} \mathrm{~J}$ in $0.1 \mathrm{M} \mathrm{NaCl}$, the range of the van der Waals force is the same as that of the electrostatic force even with a bacterium surface potential as high as $-80 \mathrm{mV}$ (and a mineral surface potential of $80 \mathrm{mV}$ ). For the most part, the electrostatic force is predicted to be larger than the van der Waals force until the separation is $<1 \mathrm{~nm}$ (data not shown on fig. 4).

Summing the electrostatic and van der Waals forces leads to the theoretical DLVO description of the interactions between goethite and either S. oneidensis or E. coli. Figure 2 provides a comparison of the measured and theoretical forces between each of the two bacteria species and goethite. Intermolecular forces between S. oneidensis and goethite are well described by the linear superposition approximation (Gregory, 1975) for a bacterium with a radius of $0.5 \mu \mathrm{m}$ and a surface potential of $-80 \mathrm{mV}(-84$ $\left.\mathrm{mC} \mathrm{m}^{-2}\right)$ interacting with a mineral that has a surface potential of $80 \mathrm{mV}\left(84 \mathrm{mC} \mathrm{m}^{-2}\right)$. The Hamaker constant for the $S$. oneidensis-goethite pair was selected as $10^{-21} \mathrm{~J}$. These parameters (surface potential values and Hamaker constant) were taken from the literature (table 1). 


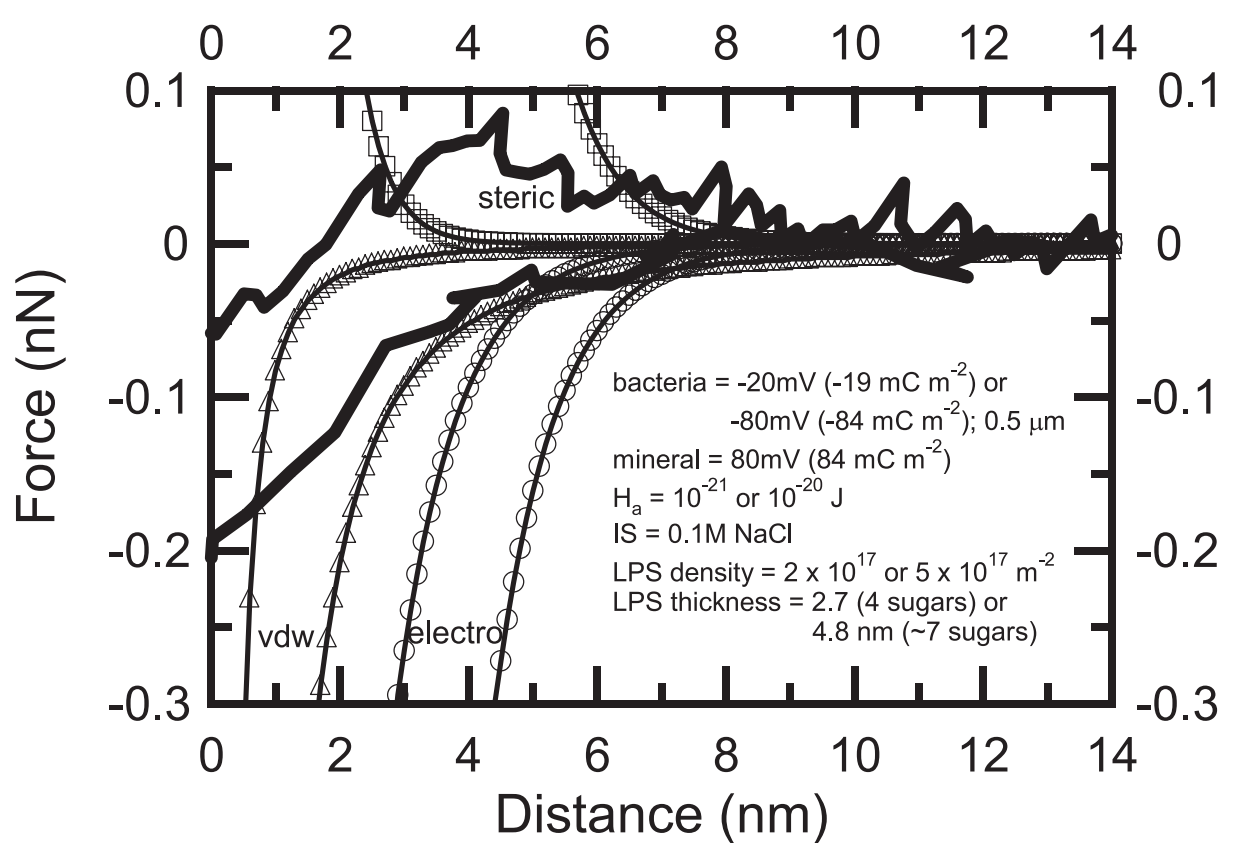

Fig. 4. Theoretically predicted force-distance relationships between goethite and E. coli or S. oneidensis. Equation (1) was used to determine the van der Waals force, where the Hamaker constant $\left(\mathrm{H}_{2}\right)$ was $10^{-21}$ or $10^{-20} \mathrm{~J}$ (two curves with open triangles). Equations (2) or (4) were used to determine the electrostatic force, where the surface potential of the mineral was $80 \mathrm{mV}$ and that of a bacterium (with a radius of $0.5 \mu \mathrm{m}$ ) was selected as $-20 \mathrm{mV}$ or $-80 \mathrm{mV}$ (two curves with open circles). The ionic strength (IS) was selected as $0.1 \mathrm{M}$ $\mathrm{NaCl}$ to calculate the electrostatic force. Equation (5) was used to determine the steric force, where the density and thickness of the lipopolysaccharide (LPS) layer was chosen as $2 \times 10^{17}$ to $5 \times 10^{17} \mathrm{~m}^{-2}$ and 2.7 $\mathrm{nm}$ to $4.8 \mathrm{~nm}$, respectively (two curves with open squares). The parameters for these three force types (van der Waals, electrostatic, and steric) were taken from table 1. Positive forces represent repulsive forces, whereas attractive forces take on a negative sign. Also shown are the observed approach forces (bold black curves) between goethite and E. coli or S. oneidensis taken from figure 2.

There is a notable discrepancy between the observed forces and theoretical description at separations $<6 \mathrm{~nm}$ for the $S$. oneidensis-goethite system (see fig. 2). The measured forces are significantly less than predicted at this length scale. A potential reason for this has to do with the spring constant of the cantilever used in these force measurements. When the actual force gradient between two surfaces exceeds the spring constant of the cantilever $\left(0.07-0.11 \mathrm{nN} \mathrm{nm}^{-1}\right.$ for the cantilevers used in this research), the cantilever jumps to contact. So called "jump to contact" features are common with force microscopy investigations, which detect attractive forces as two surfaces come together. At a distance of $\sim 6 \mathrm{~nm}$ the theoretical force gradient (the gradient between 4 and $6 \mathrm{~nm}$ is $\sim 0.125 \mathrm{nN} \mathrm{nm}^{-1}$ ) begins to exceed the spring constant of the cantilever. Therefore, the disparity between the measurements and DLVO theory may be due to the instrument itself. An alternative explanation is that the inherent surface roughness of a bacterium and/or mineral may lead to a decrease in the observed forces. Recent work on the theoretical aspects of DLVO theory suggests that a particles' surface roughness is expected to decrease the magnitude of intermolecular forces between two surfaces (Cooper and others, 2000; Hoek and others, 2003). The van der Waals and electrostatic equations (eqs 1, 2, and 4) shown in this paper were derived for smooth surfaces.

Contrary to the case with $S$. oneidensis, the E. coli-goethite system cannot be adequately described by the DLVO theory for any reasonable parameters selected from 
TABLE 1

Bacteria and mineral surface properties used to determine theoretical van der Waals, electrostatic, and steric forces between goethite and either $E$. coli or S. oneidensis.

\begin{tabular}{|c|c|c|c|}
\hline & parameter value & description & source(s) \\
\hline \multirow{5}{*}{ 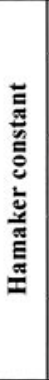 } & $10^{-21} \mathrm{~J}$ & E. coli interacting with glass in water & (Vigeant and others, 2002) \\
\hline & $\begin{array}{l}1.0 \times 10^{-21} \text { to } \\
2.3 \times 10^{-21} \mathrm{~J}\end{array}$ & $\begin{array}{l}\text { E. coli interacting with mica, glass, or polystyrene } \\
\text { in water }\end{array}$ & (Ong and others, 1999) \\
\hline & $\begin{array}{l}4.1 \times 10^{-21} \text { to } \\
6.0 \times 10^{-21} \mathrm{~J}\end{array}$ & $\begin{array}{l}\text { Gram negative bacterium interacting with quartz or } \\
\text { iron oxide in water }\end{array}$ & (Dong and others, 2002) \\
\hline & $10^{-20} \mathrm{~J}$ & $\begin{array}{l}\text { Gram negative bacterium interacting with silicon } \\
\text { nitride in water }\end{array}$ & $\begin{array}{l}\text { (Camesano and Logan, } \\
\text { 2000) }\end{array}$ \\
\hline & $6.0 \times 10^{-20} \mathrm{~J}$ & $\begin{array}{l}\text { Gram negative bacterium interacting with air } \\
\text { bubble in water }\end{array}$ & (Schafer and others, 1998) \\
\hline \multirow{9}{*}{ 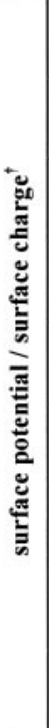 } & $\begin{array}{c}(-88 \mathrm{mV}) \\
-100 \mathrm{mCm}^{-2}\end{array}$ & Shewanella in $0.1 \mathrm{M} \mathrm{KNO}_{3}$ & (Sokolov and others, 2001) \\
\hline & $\begin{array}{l}-26 \text { to }-45 \mathrm{mV} \\
\left(-20 \text { to }-37 \mathrm{mCm}^{-2}\right)\end{array}$ & E. coli in $0.1 \mathrm{M} \mathrm{KCl}$ & (Jucker and others, 1998) \\
\hline & $\begin{array}{c}-20 \mathrm{mV} \\
\left(-15 \mathrm{mCm}^{-2}\right)\end{array}$ & E. coli in $0.2 \mathrm{M}$ aqueous buffer & (Vigeant and others, 2002) \\
\hline & $\begin{array}{l}-55 \text { to }-60 \mathrm{mV} \\
\left(-48 \text { to }-54 \mathrm{mCm}^{-2}\right)\end{array}$ & various Gram negative bacteria in $0.1 \mathrm{M}$ solution & $\begin{array}{l}\text { (Poortinga and others, } \\
\text { 2002) }\end{array}$ \\
\hline & $\begin{array}{l}-11 \text { to }-40 \mathrm{mV} \\
\left(-8 \text { to }-32 \mathrm{mCm}^{-2}\right)\end{array}$ & various Gram negative bacteria in $0.1 \mathrm{M}$ solution & (Schafer and others, 1998) \\
\hline & $\begin{array}{l}(88 \mathrm{mV}) \\
100 \mathrm{mCm}^{-2}\end{array}$ & $\mathrm{Fe}_{2} \mathrm{O}_{3}$ in $0.1 \mathrm{M} \mathrm{KCl}$ & (Barany, 1998) \\
\hline & $\begin{array}{l}(72 \text { to } 97 \mathrm{mV}) \\
70 \text { to } 120 \mathrm{mCm}^{-2}\end{array}$ & $\mathrm{FeOOH}$ in $0.1 \mathrm{M} \mathrm{NaCl}$ & $\begin{array}{l}\text { (Lumsdon and Evans, } \\
\text { 1994) }\end{array}$ \\
\hline & $\begin{array}{l}(27 \text { to } 57 \mathrm{mV}) \\
20 \text { to } 50 \mathrm{mCm}^{-2}\end{array}$ & (110) face of $\mathrm{FeOOH}$ in $0.1 \mathrm{M} \mathrm{NaCl}$ & (Felmy and Rustad, 1998) \\
\hline & $\begin{array}{l}(38 \text { to } 65 \mathrm{mV}) \\
30 \text { to } 60 \mathrm{mCm}^{-2}\end{array}$ & (021) face of $\mathrm{FeOOH}$ in $0.1 \mathrm{M} \mathrm{NaCl}$ & (Felmy and Rustad, 1998) \\
\hline \multirow{3}{*}{ 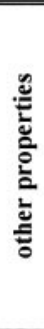 } & $2 \times 10^{17}$ LPS $\mathrm{m}^{-2}$ & $\begin{array}{l}\text { calculated LPS density based on the following } \\
\text { values: } 1,430,000 \text { LPS per cell for } E \text {. coli } \mathrm{B} / \mathrm{r} \text { and a } \\
\text { cell surface area of } 6.7 \mu \mathrm{m}^{2}\end{array}$ & $\begin{array}{l}\text { (Neidhardt and Umbarger, } \\
\text { 1996; Nikaido, 1996) }\end{array}$ \\
\hline & $5 \times 10^{17}$ LPS $\mathrm{m}^{-2}$ & $\begin{array}{l}\text { calculated LPS density based on the following } \\
\text { values: } 3,460,000 \text { LPS per cell for } E \text {. coli } \mathrm{K} 12 \text { and } \\
\text { a cell surface area of } 6.7 \mu \mathrm{m}^{2}\end{array}$ & (Nikaido, 1996) \\
\hline & 2.4 to $4.2 \mathrm{~nm}$ & $\begin{array}{l}\text { calculated LPS thickness based on the following } \\
\text { values: } 4-7 \text { hexose sugars, which make up the core } \\
\text { polysaccharide, and a length of } \sim 0.6 \mathrm{~nm} \text { for each } \\
\text { sugar residue }\end{array}$ & $\begin{array}{l}\text { (Ferrier, 1963; Nikaido, } \\
\text { 1996; Raetz, 1996; Rick } \\
\text { and Silver, 1996; Madigan } \\
\text { and others, 2003) }\end{array}$ \\
\hline
\end{tabular}

${ }^{\dagger}$ All surface potential or surface charge data are for particles in solution at $\mathrm{pH} \sim 7$. The surface potential or surface charge value in parentheses was calculated according to the Graham equation (Stumm, 1992): $\sigma=\sqrt{8 R T \varepsilon \varepsilon_{0} c \times 10^{3}} \times \sinh \left(\frac{\mathrm{z} \psi F}{2 R T}\right)$,where $R$ is the gas constant $\left(8.314 \mathrm{~J} \mathrm{~mol}^{-1} \mathrm{~K}^{-1}\right), F$ is the Faraday constant $\left(96,490 \mathrm{C} \mathrm{mol}^{-1}\right)$, and all other parameters are as defined in the text. Sources cited for surface potential measurements actually determined a particle's zeta potential $(\zeta)$ rather than a true surface potential $(\psi)$. 
table 1 . This is because the van der Waals and electrostatic forces are expected to be attractive at all separations (see fig. 4). However, the measurements reveal a repulsive force between $E$. coli and goethite at a range of 4 to $10 \mathrm{~nm}$ (see fig. 2). The observed repulsive force may be due to non-DLVO type of forces such as steric interactions (Israelachvili and McGuiggan, 1988; Israelachvili, 1992). Steric forces may arise between two particles if at least one of the particles contains a polymer layer on its surface. As the two surfaces approach one another, the polymers become confined to the intervening space and they are no longer free to move at random. This loss of dynamic movement for chain molecules creates an entropic repulsive force at close separation.

Steric interactions, like DLVO forces, have been described in terms of energydistance relationships (Alexander, 1977; de Gennes, 1987). Based on these prior descriptions, Butt and others (1999) and Camesano and Logan (2000) derived a theoretical force-distance relationship between a sphere and a flat surface, one of which is coated with a polymer. This steric force is given as (Butt and others, 1999):

$$
F(D)=50 r k_{B} T L_{0} \Gamma^{3 / 2} \mathrm{e}^{-2 \pi D / L_{0}}
$$

where $L_{0}$ is the equilibrium thickness of the polymer (in $\mathrm{m}$ ), $\Gamma$ is the density of the polymer on the surface (in $\mathrm{m}^{-2}$ ), and all other parameters are as defined above.

Figure 4 shows the steric force for a Gram-negative bacterium interacting with goethite using values for biopolymer thickness and surface density taken from the literature (table 1). The observed forces between E. coli and goethite are modeled reasonably well when the repulsive steric force is added to the van der Waals and the constant potential approximation of the electrostatic force (see fig. 2). Both the measured forces and the "extended" DLVO theory reveal an initial repulsive force between $E$. coli and goethite that is overcome by an attractive force at very close separation.

In the context of bacterial recognition of a mineral surface, which is the objective of this paper, the approach force data provide some very important information. The magnitude and range of the measured forces can be described in terms of nonspecific forces of interaction such as, van der Waals, electrostatic, and steric forces. All of these force types are very short range in these solution conditions. The bacteria must get to within 5 to $10 \mathrm{~nm}$ of goethite before the cell senses the presence of the mineral. In other words, a bacterium must come into direct physical contact with a mineral before it has a chance to recognize that surface. However, these approach force data do not provide evidence of specific interactions between goethite and either bacteria. The retraction force data, on the other hand, contain information about the energetic affinity between a bacterium and goethite and details about specific biopolymers that may form a bond with goethite.

Figure 3 illustrates the forces recorded as E. coli or S. oneidensis were pulled away from the mineral surface. Force profiles between E. coli and goethite are relatively simple showing, in most cases, that $E$. coli can be separated from the mineral within a few nanometers. S. oneidensis, conversely, remained linked to the surface of goethite for hundreds of nanometers resulting in more complicated retraction profile (see fig. 3).

The overall characteristics of retraction curves can be described in terms of the maximum force recorded at a distance of zero, the so-called "adhesion force". For the Shewanella-goethite bacteria-mineral pair, this would seem to be an oversimplification of the retraction data because the adhesion force is only one point on the entire retraction profile. The energy or work required to separate a bacterium from a mineral can be quantified by numerically integrating the retraction force profiles with respect to distance (Lower and others, 2001a). This provides a physically relevant parameter that takes into account the entire retraction data. 
Even though the surfaces of S. oneidensis and E. coli are very similar (fig. 1), there is a striking difference in the energetic affinity for goethite exhibited by these two Gram negative bacteria. Integrating force with respect to distance for retraction curves like those shown in figure 3 yields an average affinity between $E$. coli and goethite of $7 \pm 3$ attoJoules $\left(10^{-18} \mathrm{~J}\right)$. This affinity was indifferent to oxygen concentration. Ionic strength, rather than oxygen concentrations, appears to have a much stronger impact on retraction forces for E. coli (see Lower and others, 2000). Also, the work to separate the bacterium from the mineral did not change with the amount of time E. coli remained in contact with goethite (up to $30 \mathrm{~min}$ ).

The situation was very different for $S$. oneidensis. The affinity between $S$. oneidensis and goethite was determined as $144 \pm 44$ aJ $\left(10^{-18} \mathrm{~J}\right)$ under anaerobic conditions when $S$. oneidensis remained in direct physical contact with goethite for 20 to 25 minutes (see also Lower and others, this issue of the American Journal of Science). When $S$. oneidensis was placed in contact with goethite for only 5 min under anaerobic conditions, the energetic attraction was only 60 aJ (Lower and others, 2001a). The solution concentration of oxygen also impacted the energetic affinity of $S$. oneidensis towards goethite. Under aerobic conditions, only 25 aJ of energetic affinity was observed between $S$. oneidensis and goethite, regardless of the amount of "contact time" between the cells and mineral (Lower and others, 2001a). Finally, it should be noted that forces have been measured between $S$. oneidensis and diaspore $(\mathrm{AlOOH})$ (Lower and others, 2001a; Lower and others, see this issue of the American Journal of Science). Diaspore has very similar surface properties to goethite, but the Al in the mineral structure of diaspore cannot serve as a terminal electron acceptor for microorganisms. S. oneidensis expressed a significantly smaller affinity for $\mathrm{AlOOH}(\sim 40$ aJ) relative to FeOOH ( $\sim 140$ aJ, see above) under anaerobic conditions.

These energy or work determinations can be summarized into a few key points. First, $S$. oneidensis exhibits a much higher affinity for goethite relative to another Gram-negative bacterium. Second, S. oneidensis has a selective affinity for iron oxides relative to other minerals like aluminum oxides, which have very similar surface properties. Third, S. oneidensis alters its affinity for iron oxyhydroxides as a result of the oxygen concentration in the intervening solution. A higher affinity is noted for $S$. oneidensis towards goethite under anaerobic conditions when Fe(III) in the mineral is the only available terminal electron acceptor. Fourth, a period of time is necessary for $S$. oneidensis to recognize the surface of goethite. Presumably, this is due to the amount of time it takes a cell to express and/or localize macromolecules to the bacteriummineral interface. Taken together, the energy determinations suggest that $S$. oneidensis possesses a rare trait of being able to recognize certain minerals such that it expresses a selective affinity for these minerals under environmental conditions that would maximize its chance for survival in nature.

While the energy or work calculations provide a suitable means of characterizing the overall attributes of the retraction data, it would be useful if one could provide evidence that specific macromolecules, like proteins, are targeted by $S$. oneidensis to the cell-mineral interface. Such information can, in fact, be established by looking for force-signatures that are characteristic of proteins that form a bond between a bacterium and mineral. Lower and others (2005) have shown that sawtooth-like force signatures denote protein bonds between a cell and solid surface.

The retraction profiles between $E$. coli and goethite are void of all but an occasional sawtooth (see fig. 3). However, retraction profiles for S. oneidensis and goethite contain discrete sawtooth features (fig. 3). This indicates that outer membrane proteins are used by $S$. oneidensis, but not $E$. coli, to form a specific bond with goethite. Protein force-signatures are primarily detected between S. oneidensis and goethite under anaerobic conditions when Fe(III) may have served as terminal 
electron acceptor. This phenomena is described in more detail by Lower and others (see this issue of the American Journal of Science). Taken together, these observations suggest that $S$. oneidensis recognizes the surface of goethite as a terminal electron acceptor such that it increases its affinity for $\mathrm{FeOOH}$ and targets putative mineralspecific proteins to promote contact with the mineral and perhaps transfer electrons to the mineral.

\section{CONCLUSION}

The ability to probe forces between a living bacterium and another surface is providing an entirely new awareness of the way bacteria perceive solid phases such as minerals. This manuscript has presented quantitative measurements of the forces of attraction (or repulsion) between goethite and two Gram negative bacteria species: $E$. coli and $S$. oneidensis. One of these bacteria, S. oneidensis, expresses a selective affinity towards goethite under conditions that would promote its survival in the environment. Intermolecular forces measured as $S$. oneidensis approached the (010) face of goethite were very short range $(<8 \mathrm{~nm})$. This means, in essence, that $S$. oneidensis must come into physical contact before it senses the presence of the mineral surface. Once in contact with the mineral, a period of time of more than $\sim 15$ to 20 minutes is necessary for $S$. oneidensis to recognize goethite as a potential terminal electron acceptor. Such recognition is highly selective as $S$. oneidensis appears to differentiate between Fehydroxides and closely related minerals such as Al-hydroxides, which have similar surface properties but cannot serve as terminal electron acceptors. Recognition triggers the expression and/or localization of putative mineral-specific proteins that direct natural forces of affinity towards goethite, presumably to enhance electron transfer between the bacterium and Fe(III) in the crystal structure of the mineral.

\section{ACKNOWLEDGMENTS}

This work was supported by the Department of Energy (DE-FG02-04ER15590) and the National Science Foundation (EAR-0417712; EAR-0411935). B. Lower, T. Beveridge, T. Camesano, and an anonymous reviewer provided valuable input that greatly improved this manuscript. I would also like to acknowledge the support of J. Tak, without whom this would not be possible.

\section{REFERENCES}

Alexander, S. J., 1977, Adsorption of chain molecules with a polar head: A scaling description: Physique, v. 38, p. 983-987.

Arredondo, R., Garcia, A., and Jerez, C. A., 1994, Partial removal of lipopolysaccharide from Thiobacillus ferrooxidans affects its adhesion to solids: Applied and Environmental Microbiology, v. 60, p. 2846-2851.

Barany, S., 1998, Complex electrosurface investigations of dispersed microphases: Advances in Colloid and Interface Science, v. 75 , p. $45-78$.

Beveridge, T. J., 1981, Ultrastructure, chemistry, and function of the bacterial wall: International Review of Cytology, v. 72, p. 229-317.

_ 1999, Structures of Gram-negative cell walls and their derived membrane vesicles: Journal of Bacteriology, v. 181, p. 4725-4733.

Butt, H. J., Jaschke, M., and Ducker, W., 1995, Measuring surface forces in aqueous electrolyte solution with the atomic force microscope: Bioelectrochemistry and Bioenergetics, v. 38, p. 191-201.

Butt, H. J., Kappl, M., Mueller, H., Raiteri, R., Meyer, W., and Ruhe, J., 1999, Steric forces measured with the atomic force microscope at various temperatures: Langmuir, v. 15, p. 2559-2565.

Camesano, T. A., and Logan, B. E., 2000, Probing bacterial electrosteric interactions using atomic force microscopy: Environmental Science and Technology, v. 34, p. 3354-3362.

Cooper, K., Ohler, N., Gupta, A., and Beaudoin, S., 2000, Analysis of contact interactions between a rough deformable colloid and a smooth substrate: Journal of Colloid and Interface Science, v. 222, p. 63-74.

de Gennes, P. G., 1987, Polymers at an interface: A simplified view: Advances in Colloid and Interface Science, v. 27, p. 189-209.

Derjaguin, B. V., and Landau, L. D., 1941, Theory of the stability of strongly charged lyophobic sols and the adhesion of strongly charged particles in solutions of electrolytes: Acta Physicochim URSS, v. 14, p. 733-762. 
Devasia, P., Natarajan, K. A., Sathyanarayana, D. N., and Rao, G. R., 1993, Surface-Chemistry of ThiobacillusFerrooxidans Relevant to Adhesion on Mineral Surfaces: Applied and Environmental Microbiology, v. 59 , p. $4051-4055$.

Dong, H. L., Onstott, T. C., Ko, C. H., Hollingsworth, A. D., Brown, D. G., and Mailloux, B. J., 2002, Theoretical prediction of collision efficiency between adhesion-deficient bacteria and sediment grain surface: Colloids and Surfaces B-Biointerfaces, v. 24, p. 229-245.

Dziurla, M. A., Achouak, W., Lam, B. T., Heulin, T., and Berthelin, J., 1998, Enzyme-linked immunofiltration assay to estimate attachment of Thiobacilli to pyrite: Applied and Environmental Microbiology, v. 64 , p. 2937-2942.

Elimelech, M., Gregory, J., Jia, X., and Williams, R., 1995, Particle Deposition and Aggregation: Measurement, Modeling, and Simulation: Oxford, Butterworth-Heinemann, 441 p.

Ellen, R. P., Lepine, G., and Nghiem, P. M., 1997, In vitro models that support adhesion specificity in biofilms of oral bacteria: Advances in Dental Research, v. 11, p. 33-42.

Felmy, A. R., and Rustad, J. R., 1998, Molecular statics calculations of proton binding to goethite surfaces: Thermodynamic modeling of the surface charging and protonation of goethite in aqueous solution: Geochimica et Cosmochimica Acta, v. 62, p. 25-31.

Ferrier, W., 1963, The crystal and molecular structure of [beta]-d-glucose: Acta Crystallographica, v. 16, p. 1023-1031.

Gregory, J., 1975, Interaction of unequal double layers at constant charge: Journal of Colloid and Interface Science, v. 51, p. 44-51.

Hoek, E. M. V., Bhattacharjee, S., and Elimelech, M., 2003, Effect of membrane surface roughness on colloid-membrane DLVO interactions: Langmuir, v. 19, p. 4836-4847.

Hogg, R. I., Healey, T. W., and Fuerstenau, D. W., 1966, Mutual coagulation of colloidal dispersions: Transactions of the Faraday Society, v. 62, p. 1638-1651.

Israelachvili, J., 1992, Intermolecular and Surface Forces: London, Academic Press, $450 \mathrm{p}$

Israelachvili, J. N., and McGuiggan, P. M., 1988, Forces between surfaces in liquids.: Science, v. 241, p. 795-800.

Jucker, B. A., Zehnder, A. J. B., and Harms, H., 1998, Quantification of polymer interactions in bacterial adhesion: Environmental Science and Technology, v. 32, p. 2909-2915.

Kendall, T. A., and Lower, S. K., 2004, Forces between minerals and biological surfaces in aqueous solution: Advances in Agronomy, v. 82, p. 1-54.

Kolenbrander, P. E., 1989, Surface recognition among oral bacteria: Multigeneric coaggregations and their mediators: Critical Reviews in Microbiology, v. 17, p. 137-159.

Leckband, D., and Israelachvili, J., 2001, Intermolecular forces in biology: Quarterly Reviews of Biophysics, v. 34, p. 105-267.

Lovley, D. R., 1991, Dissimilatory Fe(III) and Mn(IV) reduction: Microbiological Reviews, v. 55, p. 259-287.

Lower, B. H., Yongsunthon, R., Vellano, III, F. P., and Lower, S. K., 2005, Simultaneous force and fluorescence measurements of a protein that forms a bond between a living bacterium and a solid surface: Journal of Bacteriology, v. 187, p. 2127-2137.

Lower, S. K., Tadanier, C. J., and Hochella, M. F., 2000, Measuring interfacial and adhesion forces between bacteria and mineral surfaces with biological force microscopy: Geochimica et Cosmochimica Acta, v. 64 , p. 3133-3139.

Lower, S. K., Hochella, M. F., and Beveridge, T. J., 2001a, Bacterial recognition of mineral surfaces: Nanoscale interactions between Shewanella and $\alpha$-FeOOH: Science, v. 292, p. 1360-1363.

Lower, S. K., Tadanier, C. J., and Hochella, M. F., 2001b, Dynamics of the mineral-microbe interface: Use of biological force microscopy in biogeochemistry and geomicrobiology: Geomicrobiology Journal, v. 18, p. 63-76.

Lower, S. K., Hochella, M. F., Jr., Banfield, J. F., and Rosso, K., 2002, Nanogeoscience: From the movement of electrons to lithosphere plates. Eos: Transactions of the American Geophysical Union, v. 83, p. 53-56.

Lumsdon, D. G., and Evans, L. J., 1994, Surface complexation model parameters for goethite (a-FeOOH): Journal of Colloid and Interface Science, v. 164, p. 119-125.

Madigan, M. T., Martinko, J. M., and Parker, J., 2003, Brock Biology of Microorganisms: Upper Saddle River, New Jersey, Prentice Hall, 1019 p.

Myers, C. R., and Myers, J. M., 1992, Localization of cytochromes to the outer membrane of anaerobically grown Shewanella Putrefaciens MR-1: Journal of Bacteriology, v. 174, p. 3429-3438.

1993, Ferric reductase is associated with the membranes of anaerobically grown Shewanella putrefaciens MR-1: Fems Microbiology Letters, v. 108, p. 15-22.

— 1997, Outer membrane cytochromes of Shewanella putrefaciens MR-1: Spectral analysis, and purification of the 83-kDa $c$-type cytochrome: Biochimica et Biophysica Acta, v. 1326, p. 307-318.

_ 2003, Cell surface exposure of the outer membrane cytochromes of Shewanella oneidensis MR-1: Letters in Applied Microbiology, v. 37, p. 254-258.

Myers, C. R., and Nealson, K. H., 1990, Respiration-linked proton translocation coupled to anaerobic reduction of manganese(IV) and iron(III) in Shewanella putrefaciens MR-1: Journal of Bacteriology, v. 172 , p. $6232-6238$.

Myers, J. M., and Myers, C. R., 1998, Isolation and sequence of omcA, a gene encoding a decaheme outer membrane cytochrome $c$ of Shewanella putrefaciens MR-1, and detection of omcA homologs in other strains of S. putrefaciens: Biochimica et Biophysica Acta, v. 1373, p. 237-251.

- 2001, Role for outer membrane cytochromes OmcA and OmcB of Shewanella putrefaciens MR-1 in reduction of manganese dioxide: Applied and Environmental Microbiology, v. 67, p. 260-269.

Neidhardt, F. C., and Umbarger, H. E., 1996, Chemical composition of Escherichia coli, in Neidhardt, F. C., editor, Escherichia coli and Salmonella: Cellular and Molecular Biology: Washington, D. C., ASM Press, p. 13-14. 
Nikaido, H., 1996, Outer membrane, in Neidhardt, F. C., editor, Escherichia coli and Salmonella: Cellular and Molecular Biology: Washington, D. C., ASM Press, p. 29-47.

Ohmura, N., Kitamura, K., and Saiki, H., 1993, Selective adhesion of Thiobacillus ferrooxidansto pyrite: Applied and Environmental Microbiology, v. 59, p. 4044-4050.

Ohmura, N., Tsugita, K., Koizumi, J. I., and Saiki, H., 1996, Sulfur-binding protein of flagella of Thiobacillus ferrooxidans: Journal of Bacteriology, v. 178, p. 5776-5780.

Ong, Y. L., Razatos, A., Georgiou, G., and Sharma, M. M., 1999, Adhesion forces between E. coli bacteria and biomaterial surfaces: Langmuir, v. 15, p. 2719-2725.

Pink, D. A., Hansen, L. T., Gill, T. A., Quinn, B. E., Jericho, M. H., and Beveridge, T. J., 2003, Divalent calcium ions inhibit the penetration of protamine through the polysaccharide brush of the outer membrane of Gram- negative bacteria: Langmuir, v. 19, p. 8852-8858.

Poortinga, A. T., Bos, R., Norde, W., and Busscher, H. J., 2002, Electric double layer interactions in bacterial adhesion to surfaces: Surface Science Reports, v. 47, p. 3-32.

Raetz, C. R. H., 1996, Bacterial lipopolysaccahrides: A remarkable family of bioactive macroamphiphiles, in Neidhardt, F. C., editor, Escherichia coli and Salmonella: Cellular and Molecular Biology: Washington, D. C., ASM Press, p. 1035-1063.

Rick, P. D., and Silver, R. P., 1996, Enterobacterial common antigen and capsular polysaccharides, in Neidhardt, F. C., editor, Escherichia coli and Salmonella: Cellular and Molecular Biology: Washington, D. C., ASM Press, p. 104-122.

Schafer, A., Harms, H., and Zehnder, A. J. B., 1998, Bacterial accumulation the air-water interface: Environmental Science and Technology, v. 32, p. 3704-3712.

Sokolov, I., Smith, D. S., Henderson, G. S., Gorby, Y. A., and Ferris, F. G., 2001, Cell surface electrochemical heterogeneity of the Fe(III)- reducing bacteria Shewanella putrefaciens: Environmental Science and Technology, v. 35, p. 341-347.

Stoica, O., Tuanyok, A., Yao, X. W., Jericho, M. H., Pink, D., and Beveridge, T. J., 2003, Elasticity of membrane vesicles isolated from Pseudomonas aeruginosa: Langmuir, v. 19, p. 10916-10924

Stumm, W., 1992, Chemistry of the Solid-Water Interface: New York, John Wiley and Sons, Inc., 428 p.

Vargas, M., Kashefi, K., Blunt-Harris, E. L., and Lovley, D. R., 1998, Microbiological evidence for Fe(III) reduction on early Earth: Nature, v. 395, p. 65-67.

Verwey, E. J., and Overbeek, J. T. G., 1948, Theory of the Stability of Lyophobic Colloids: Amsterdam, Elsevier Publishing, 205 p.

Vigeant, M. A. S., Ford, R. M., Wagner, M., and Tamm, L. K., 2002, Reversible and irreversible adhesion of motile Escherichia coli cells analyzed by total internal reflection aqueous fluorescence microscopy: Applied and Environmental Microbiology, v. 68, p. 2794-2801.

Whittaker, C. J., Klier, C. M., and Kolenbrander, P. E., 1996, Mechanisms of adhesion by oral bacteria: Annual Review of Microbiology, v. 50, p. 513-552. 